\title{
EFFECT OF ACTIVITY-BASED INSTRUCTIONAL STRATEGY ON SENIOR SECONDARY SCHOOL STUDENTS' RETENTION IN CIRCLE GEOMETRY IN ABUJA, NIGERIA
}

\author{
Durojaiye, David Sunday, \\ Jekayinfa, Olatunji Jamesi, \\ Oloda Festus Sunday Smart \\ Mathematical Sciences Education Programme, \\ National Mathematical Centre, \\ Abuja, Nigeria
}

\begin{abstract}
:
This study investigated the effects of activity-based instructional strategy on senior secondary schools students' retention in circle geometry. The study employed a quasiexperimental design of the type pre-test, post-test groups design. The sample for the study comprised of 162 senior secondary 2 students drawn from two randomly selected co-educational schools in Federal Capital Territory, Nigeria. The research instrument was Mathematics Retention Test (MRT) containing items adapted from standardized WAEC questions. The test-retest method was employed for the reliability of the test instrument. The Pearson Product Moment Correlation Coefficient $(\mathrm{r})=0.86$ was obtained. Data collected were analyzed using t-test. The finding of this study revealed that there was a significant difference in the retention of students taught circle geometry using activitybased instructional strategy (ABIS) and the students taught circle geometry using conventional methods in favour of the students taught using ABIS. The study also indicated that there was no significant difference between the retention of male and female students in the experimental group who were taught circle geometry using ABIS. It was therefore recommended that mathematics teachers should use strategies that will encourage the active participation of students in mathematics classes such as ABIS which in turn would enhance retention. Also, governments at all levels should organize trainings and/or workshops for mathematics teachers on the use of ABIS in teaching mathematics.
\end{abstract}

Keywords: instructional strategy, ABIS, retention

i Correspondence: email olatunjek@gmail.com, oluk4christ@gmail.com 


\section{Introduction}

Mathematics is the bedrock to which the technological development of any nation is hinged thus, the importance of mathematics for any nation aspiring for scientific and technological advancement cannot be over emphasized. The importance placed on mathematics in both primary and secondary school curriculum is a type that requests that the subject be thoroughly taught at these levels. Mathematics is so important in our daily lives that any nation that would want to make any significant progress in science, technology and modern development must take seriously its teaching in both primary and secondary levels. Salman \& Adeniyi (2012) affirmed that without Mathematics there is no science and without science there is no technology and without technology, there is no modern society. Kolawole \& Ajetunmobi (2014) opined that different nations across the globe are at the present time categorized as either first-world, second-world or thirdworld on the basis of each nation's level of development in science and technology, which are more often than not, powered by sophisticated numerical manipulations that always employ Mathematics as its basic tool.

In spite of the importance of Mathematics, Nigerian students at the Secondary School level are not doing well both in internal and external examinations as a result of poor understanding and retention of the subject. Nwadiage (2010), Kolawole \& Ajetunmobi (2014) and Jekayinfa (2019) have attested to the fact that learners' achievement and retention in Mathematics at primary and secondary school levels in both internal and external examinations have remained unsatisfactory.

Studies have revealed that many of the strategies employed in teaching mathematics in schools by mathematics teachers promote rote learning and memorization instead of enhancing retention. Akuboilo (2004) opined that any instructional model and strategy, which elicits adequate students' participation, has a profound effect on students' retention. Odili (2006) opined that rote learning and memorization are caused by too much theoretical expressions or formulae by the mathematics teacher while learners remain passive spectators. The researcher further opined that mathematics concepts are believed to be the concept that cannot be learnt by mere memorization through rote learning. The major problem that will be faced by the students learning through this method is inability to retain, remember and recall what they have learnt (Odili, 2006).

According to Bichi (2002) as cited in Azuka (2012), retention is the process by which information is stored and retrieved. Retention means storage of information over some period of time when it will be used. It can therefore be deduced from the above researchers that there is no retention until recall of stored information is done. Azuka (2011) asserted that one of the instructional strategies that can enhance retention is the activity-based instructional strategy (ABIS). This researcher described ABIS as a range of pedagogical strategies to teaching. The researcher explained that the core grounds of ABIS include the condition that learning should be based on doing some hands-on experiments and activities. ABIS is a child-centered approach. It is an approach in which 
the child is actively involved in participating mentally and physically. Learning by doing is the main focus in this strategy. ABIS is a strategy adopted by a teacher to emphasize his or her method of teaching through activity in which the students participate vigorously and bring about efficient learning experiences (Wikipedia, 2011).

According to Thayniath (2016) a mathematics teacher in ABIS is responsible for:

- The planning and preparation to Identify learning outcomes;

- Selecting the appropriate activities to stimulate the learners;

- Mechanisms within the group; and

- Promoting cooperation in carrying out the activity.

Consequently, it could be concluded that in ABIS, the teacher plays the role of an organizer, planner and knowledge facilitator. The teacher gives the students instructions on what activities to carry out during mathematics lessons and he/she (teacher) tours round the class to make sure that the activities are being carried out as instructed (Durojaiye, Salman, Jekayinfa, \& Okwuoza, 2017). According to Thayniath (2016), the ABIS affords the learners the opportunity for interactive learning, participation in educational objectives, collaboration with others to develop good organizational skills, helps learner to focus more, increases attention and creates an optimistic environment to respond to the educational settings for these different activities and demonstration of enthusiasm for seeking new knowledge.

In Nigeria and even in the world at large, the issue of gender inequality in science, technology and mathematics education (STME) has not tilted to one direction. Literature about gender and retention of contents of school subjects exist with different views and findings. While some studies have shown that the male students retained better than their female counterparts other studies have shown the other way round. Still, some studies have shown no significant difference in the retention of male and female students. For example, Divjak (2010) carried out a study on sustainable student retention and gender issues in mathematics for ICT study and reported that there existed minor significant gender differences in different skills. The researcher found that the pass rate for female students is constantly higher than that for male students. According to Divjak (2010), the reason for the better performance of the female students have been investigated and traced to better retention level among others. In the same vein, Owodunni \& Ogundola (2013) in their study on gender differences in the achievement and retention of Nigerian students exposed to concept in electronic works trade through reflective inquiry instructional technique found and reported that the mean score of boys was higher than the mean score of girls taught electronic works trade using reflective inquiry instructional technique, but the mean score of girls was higher than the that of boys in the test for retention of learning. However, Ugwanyi (2016) in his study on effect of using algebraic factorization game instructional strategy on students' retention in algebra found that there was no significant difference in the retention of male and female students. 


\section{Statement of the Problem}

Students at any level would find it difficult to perform satisfactorily well when retention of academic contents is very poor. Iji (2010) asserted that retention and performance go together because retention of any academic content learnt enhances performance. The researcher further affirmed that retention is measured in collaboration with performance. Studies have shown that geometry is one of the branches of mathematics that teachers find difficult to teach and consequently students do not perform well in it. This, perhaps, may be because of poor retention of the topic by students as a result of poor teaching strategies by mathematics teachers.

Azuka, Durojaiye, Okwuoza, \& Jekayinfa (2013b) carried out an investigation into perceived difficult topics by mathematics teachers in Federal Unity Schools in Nigeria. These researchers reported that $58 \%$ of the Mathematics teachers in Federal Unity Schools in Nigeria specifically considered circle geometry as difficult to teach. Thus, if a teacher finds a topic difficult to teach he/she may not use appropriate strategies that would enhance retention.

In order to find solutions to the problems of poor retention and hence, performance occasioned by inappropriate teaching methods and strategies in mathematics, researchers such as Shiri \& Badri (2013), Borode (2014), Azuka, Okwuoza, Jekayinfa, \& Durojaiye (2013c), Ismail (2014) and so on have carried out some studies on activity-based instructional strategy. Unfortunately, most of these empirical studies were focused on science subjects, English and French Languages. Very few studies on activitybased instructional strategy were carried out on mathematics. Even the few ones on mathematics were neither on geometry nor on senior secondary mathematics. Therefore, there is need for an empirical study on teaching geometry using activity-based instructional strategy in senior secondary schools.

\subsection{Purpose of the Study}

The main purpose of this study is to find out the effect of activity-based instructional strategy on the retention of students taught Circle Geometry. Specifically, this study will also determine the:

1. students' level of retention when taught circle geometry using the ABIS,

2. influence of gender on the retention of students taught circle geometry using ABIS.

\subsection{Research Questions}

Two research questions were raised for this study:

1. What is the difference between the mean retention scores of students taught circle geometry using ABIS and those taught using conventional method?

2. Is there any difference between the mean retention knowledge of male and female students when taught circle geometry using ABIS? 


\subsection{Research Hypotheses}

Two research hypotheses were formulated for this study:

$\mathrm{H}_{01}$ : There is no significant difference between the mean retention scores of students taught circle geometry using ABIS and those taught using the conventional method.

$H_{02}$ : There is no significant difference between the MRT mean scores of male and female students when taught circle geometry using ABIS.

\section{Methodology}

This study employed a quasi-experimental design of the type pre-test, post-test, nonrandomized and non-equivalent control group. The design is $2 \times 3$ quasi-experimental design. Two groups were involved: the experimental group and the control group. The two groups were subjected to pre-test and post-test. The independent variable was the use of ABIS to teach circle geometry and also the treatment for the experimental group while the conventional method of teaching was used for the control group. The conventional method of teaching in this study is the usual way mathematics teachers teach circle geometry without carrying out any activities leading to any discovery. The dependent variable was the students' performance in pre-test and retention test.

The target population for this study consisted of all senior secondary two (SS 2) students in Abuja Municipal Area Council (AMAC), Abuja, Nigeria. The choice of SS 2 students was appropriate for this study since it is at this class that circle geometry is taught. A multistage stratified sampling technique was used for the study. In the first stage, five co-educational schools were randomly selected using the Simple Random Sampling Technique and the pre-test administered to the SS 2 students while in the second stage, two schools with equivalent mean scores from the five schools were selected for this study. In the third stage, the two schools with equivalent mean scores were further randomly assigned to experimental and control groups. Intact classes of the selected schools were used for the study.

A total of 162 (one hundred and sixty-two) senior secondary two (SS 2) students were involved in the study. The selected sample schools had 79 (seventy nine) students (43males and 36 females) for the experimental group and 83 (eighty three) students (45males and 38 females) for the control group. The research instrument for this study was the Mathematics Retention Test (MRT) adapted from past WAEC questions on circle geometry. It contains 30 (thirty) multiple choice items. The reliability of the instrument was carried out on another intact class in a school in AMAC that did not participate in the main study using the test re-test method. The Pearson Product Moment Correlation Coefficient statistical analysis was used to analyze the scores obtained and a reliability coefficient of 0.86 was obtained and the instrument was considered appropriate for the study.

The study lasted for a period of six weeks. Four weeks were used for teaching circle geometry while the first and the sixth weeks were used to administer the pre-test 
and post-test respectively for the two groups. The researcher allowed a four weeks interval before administering the MRT.

The experimental group was exposed to the treatment involving the use of ABIS. Here the researcher only gave instructions on the activities to be performed by the students. The students carried out the activities individually under the guidance of the researcher. For example, in proving the theorem that: opposite angles of a cyclic quadrilateral are supplementary or angles in opposite segments are supplementary. The researchers drew the circle below on the board and asked the students to carry out the following activities with the use of their sets of mathematical instrument:

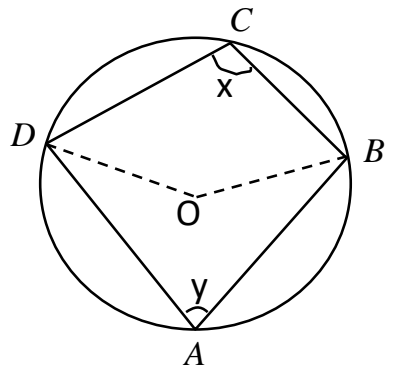

- Draw exactly the circle on the board in your notebook. Use any radius of your choice. (Researcher toured round the class to guide the students as they draw the circle in their notebooks).

- Use your protractor to measure $<$ DCB from the circle you drew in your notebook. i.e. angle $x$ (Researcher guide the students to measure the angle).

- Use your protractor to measure $\angle \mathrm{DAB}$ from the circle. i.e. angle y (Researcher guide the students to measure the angle).

- The researcher asked the students to give the results of their measurements. (The researcher writes out some of the students' responses in a tabular form on the board. See sample of students' responses on table 2 below).

Table 1: Results of students' measurements of angles ACB and AOB

\begin{tabular}{|l|c|c|c|}
\hline Students & $<$ DCB $(\mathbf{x})$ & $<$ DAB $(\mathbf{y})$ & $\mathbf{x}+\mathbf{y}$ \\
\hline 1 & $102^{0}$ & $78^{0}$ & $180^{0}$ \\
\hline 2 & $77^{0}$ & $103^{0}$ & $180^{0}$ \\
\hline 3 & $100^{0}$ & $80^{0}$ & $180^{0}$ \\
\hline 4 & $67.4^{0}$ & $116.6^{0}$ & $180^{0}$ \\
\hline 5 & $83^{0}$ & $97^{0}$ & $180^{0}$ \\
\hline 6 & $90^{0}$ & $90^{0}$ & $180^{0}$ \\
\hline 7 & $78.2^{0}$ & $101.8^{0}$ & $180^{0}$ \\
\hline 8 & $123^{0}$ & $57^{0}$ & $180^{0}$ \\
\hline 9 & $98^{0}$ & $82^{0}$ & $180^{0}$ \\
\hline 10 & $69.7^{0}$ & $110.3^{0}$ & \\
\hline
\end{tabular}

- The researcher asked the students to state their observations from the table above. (Researcher only moderated the responses of the students. At this point the researchers lead the students to discover that $\angle A C B+\angle D A B)=180^{\circ}$. i.e. $x+y=180^{\circ}$. 
- The researcher asked the students to suggest rules (theorem) for the above scenario. (The researcher also moderated the responses of the students leading them to the theorem that opposite angles of a cyclic quadrilateral are supplementary.

The control group was taught circle geometry using the conventional method of instruction. A post-test was administered to all the students of the two groups. The MRT was also administered four weeks after the post test. The data collected from the pre-test and RPT scores for both the experimental and control groups were used to answer the research questions and testing of the hypotheses. The mean retention scores and standard deviation were used to answer the research questions while the hypotheses were tested using the t-test statistic.

\section{Results}

Research Question 1: What is the difference between the mean retention scores of students taught circle geometry using ABIS and those taught using the conventional method?

Table 2: Mean, standard deviation and mean difference of experimental and control groups

\begin{tabular}{|c|l|c|c|c|c|}
\hline Test & \multicolumn{1}{|c|}{ Group } & No & Mean & SD & Mean Difference \\
\hline \multirow{2}{*}{ MRT } & Experimental & 79 & 19.53 & 4.19 & \multirow{2}{*}{7.41} \\
\cline { 2 - 5 } & Control & 83 & 12.12 & 3.15 & \\
\hline
\end{tabular}

Table 2 shows the retention mean scores of students taught circle geometry using ABIS as 19.53 while the retention means scores of the students in the control group is 12.12 . The mean difference is 7.41 .

Research Question 2: Is there any difference between the mean retention scores of male and female students when taught circle geometry using ABIS?

Table 3: Mean, standard deviation and mean difference of experimental and control groups based on gender

\begin{tabular}{|l|c|c|c|c|}
\hline \multicolumn{1}{|c|}{ Variable } & Number & Mean & SD & Mean Difference \\
\hline Male & 43 & 19.63 & 3.77 & 0.21 \\
\hline Female & 36 & 19.42 & 4.70 & \\
\hline
\end{tabular}

Table 3 reveals a mean difference of 0.21 in the retention test of male and female students taught circle geometry using ABIS. The male students had a retention mean score of 19.63 while their female counterparts had a retention mean score of 19.42 .

Hypothesis one $\left(\mathbf{H}_{01}\right)$ : There is no significant difference between the mean retention scores of students taught circle geometry using ABIS and those taught using the conventional method. 
Table 4: t-test-analysis indicating difference between retention test mean scores of students' taught circle geometry using ABIS and those taught using conventional method

\begin{tabular}{|l|l|c|c|c|c|c|c|c|c|}
\hline Test & Group & $\mathbf{N}$ & Mean & SD & S Error & Mean difference & Df & t-value & p-value \\
\hline \multirow{2}{*}{ MRT } & Experimental & 79 & 19.53 & 4.19 & 0.47 & 7.41 & \multirow{2}{*}{160} & \multirow{2}{*}{12.77} & \multirow{2}{*}{0.000} \\
\cline { 2 - 10 } & Control & 83 & 12.12 & 3.15 & 0.35 & & & \\
\hline
\end{tabular}

Table 4 reveals that statistical significance exists between the students taught circle geometry with ABIS and their counterparts in the control group who were taught using the conventional method with regard to their retention level. It shows that the $\mathrm{t}$-value $=$ 12.77 , degree of freedom $=160$ and $p$-value $=0.00$. Since the $p$-value is less than 0.05 level of significance, the null hypothesis is rejected. Thus, there is a significant difference in the mean retention scores of students taught circle geometry using ABIS and those taught using the conventional method.

Hypothesis two $\left(\mathbf{H}_{\mathbf{0} 2}\right)$ : There is no significant difference between the Mathematics Retention Test mean scores of male and female students when taught Circle geometry using ABIS.

Table 5: t-test analysis indicating difference between mathematics retention test mean scores of male and female students in mathematics when taught geometry using ABIS

\begin{tabular}{|l|c|c|c|c|c|c|c|c|c|}
\hline Variable & $\mathbf{N}$ & Mean & SD & S Error & Mean difference & df & t-test & P-value & Decision \\
\cline { 1 - 5 } Male & 43 & 19.63 & 3.77 & 0.57 & 0.21 & 77 & 0.22 & \multirow{2}{*}{0.825} & \multirow{2}{*}{ Ho2 Accepted } \\
\cline { 1 - 6 } Female & 36 & 19.42 & 4.70 & 0.78 & & & & \\
\hline
\end{tabular}

Table 5 shows that the $t$-value is 0.22 , degree of freedom is 77 and p-value is 0.825 . Since the p-value is greater than 0.05 level of significance, the null hypothesis is not rejected. Thus, there is no significant difference between the Mathematics Retention Test mean scores of male and female students when taught Circle geometry using ABIS.

\section{Summary of Major Findings}

The main findings of this study as obtained from the analyses of the data are summarized as follows:

1. There was a significant difference in the retention level of students taught circle geometry in mathematics using ABIS and those taught circle geometry in mathematics using conventional method in favour of those taught using ABIS. This implies that teaching mathematics using ABIS in AMAC enhances more retention in the subject content than the conventional method.

2. The mean retention test score of male and female students was not significantly different. This implies that male and female students had equal level of retention in AMAC when taught circle geometry with ABIS. 


\section{Discussion}

The findings of this study have revealed that the ABIS is a potent strategy to be used in teaching mathematics in schools. The study exposed that students taught circle geometry using ABIS had higher retention than the students taught circle geometry with conventional method. This is probably so because the students in the experimental group were allowed to actively participate in the learning and teaching process, they were provided with all the learning materials needed to learn circle geometry. They were also allowed to interact and manipulate their learning materials freely and to think and discover the theorems in circle geometry themselves. This finding buttressed the finding of Ugwuanyi (2016) which found significant difference in retention in favour of the experimental group who were taught algebra using algebraic factorization game instructional strategy.

On the basis of gender, the findings of this study showed that there was no significant difference in the mean scores of retention performance test of male and female students in the experimental group who were taught circle geometry using the ABIS. This indicated that male and female students performed and retained equally when taught circle geometry with the use of ABIS. Also, these findings agreed with the reports of Ugwuanyi (2016) which revealed that there was no statistically significant difference in the retention of male and female students when they were taught algebra using algebraic factorization game instructional strategy. However, the finding of this study contradicted those of Divjak (2010) and Owodunni and ogundola (2013) who found and reported in their various studies; significant difference in the retention of male and female students in favour of female students.

\subsection{Recommendation}

Based on the findings of this study, the following recommendations were made:

1. Mathematics teachers should use strategies such as the ABIS that would actively involve students in the teaching and learning process of Mathematics because the more students are involved the higher the retention level. It has been found that "the more the senses of learners are stimulated, the more the learners learn, and the longer he/she retains and the better he/she performs" (Prem, 2012).

2. Male and female students should be equally engaged in the teaching and learning of Mathematics when using ABIS. Female students should be involved in the classroom activities and should be allowed to manipulate instructional materials freely as their male counterparts since ABIS is not bias against gender.

3. Since it has been revealed by the study that ABIS enhances retention better than the conventional method of teaching, it is therefore recommended that government at all levels should organize workshops for mathematics teachers on how to use ABIS in teaching mathematics. 


\section{Conflict of Interest Statement}

The authors hereby state that there is no conflict of interest in respect of the paper titled "Effect of Activity-Based Instructional Strategy on Senior Secondary School Students' Retention in Circle Geometry in Abuja, Nigeria".

\section{About the Authors}

Durojaiye, David Sunday is a Research Fellow II officer from the Mathematical Sciences Education Programme at the National Mathematical Centre, Abuja. He is currently undertaking his Ph.D studies in Mathematics Education at the University of Abuja, Abuja, Nigeria. He is a seasoned Mathematics Teacher and a Researcher in the area of Mathematics Education. He has researched extensively in the area of Teaching and Learning of Mathematics especially at the primary and secondary school education levels with emphasis on developing new strategies in the teaching and learning of the subject with a view to improving Students' performance. He is a registered member of Mathematical Association of Nigeria (MAN).

Jekayinfa, Olatunji James (PhD) is a Mathematics Education expert who also works with the National Mathematical Centre, Abuja in the Mathematical Sciences Education Programme. He is presently a Research Fellow I officer and his area of Research interest ranges from developing new strategies of Mathematics teaching to develop students' interest in Mathematics, to innovating, developing and deploying technology in the teaching and learning of Mathematics with a view to boosting Students' interest and ultimately enhancing their performance in the subject. He is a registered member of Mathematical Association of Nigeria (MAN).

Oloda, Festus Sunday Smart (PhD) is a Research Fellow I in the Mathematical Sciences Education Programme at the National Mathematical Centre (NMC), Abuja, Nigeria. He is an expert in Tests and Measurement. His area of Research interest is in self-assessment of students in mathematics, Differential item functioning (DIF) of test items in mathematics, and Determinants of student's performance in mathematics. He is a registered member of the Teacher's Registration Council of Nigeria (TRCN) and Mathematical Association of Nigeria (MAN).

\section{References}

Akuboilo, D. U. (2004). The effect of problem solving instructional strategies on students' achievement and retention in Biology with respect to location in Enugu. Journal of Science Teachers' Association of Nigeria, 39(2), 94-100.

Azuka, B. F. (2011). Methods and Strategies of Teaching Mathematics in Schools. In S. O. Ale, Capacity building workshop manual for primary schools' mathematics teachers in Nigeria (pp. 41-54). Abuja: Mike Marvelous Press Limited.

Azuka, B. F. (2012). How students can retain mathematical knowledge in schools. Abacus, the Journal of Mathematical Association of Nigeria, 37(1), 89-94. 
Azuka, B. F., Durojaiye, D. S., Okwuoza, S. O., \& Jekayinfa, O. J. (2013b). Attitude of secondary school mathematics teachers toward the teaching of mathematics in Nigeria. Journal of Mathematical Sciences Education, 2(1), 181-191.

Azuka, B. F., Okwuoza, S. O., Jekayinfa, J. O., \& Durojaiye, D. S. (2013c). Difficulty levels of topics in the new senior secondary school mathematics curriculum as perceived by mathematics teachers of federal unity schools in Nigeria. Journal of Education and Practice, 4(17), 38-52.

Bichi, S. S. (2002). Effects of problem solving strategy and enriched curriculum on evaluation concepts among secondary school students . Unpublished Ph.D. Thesis, Faculty of education, Ahmadu Bello University, Zaria, 102-104.

Borede, B. R. (2014). Effects of lecture and activity- based Methods on the Attitude of Junior Secondary School Students to Essay Writing in French . European Journal of Educational Studies, 6(1), 1-5. Retrieved from http://www.ozelacademy.com/ejes.v6.i1-5

Divjak, B. (2010). Sustaining students' retention and gender issues in mathematics for ICT study. International journal of Mathematical Education in Science and Technology, 3, 143-157.

Durojaiye, D. S., Salman, M. F., Jekayinfa, O. J., \& Okwuoza, S. O. (2017). Effect of activitybased instructional strategy on senior school students' performance in circle geometry in Abuja, Nigeria. Journal of Mathematical Science Education, National Mathematical Centre, Abuja, Nigeria, 3(1).

Iji, C. O. (2010). Approach on senior secondary school geometry. Journal of Science Teachers Association of Nigerian, 3(2), 45-50.

Ismail, Y. (2014). Impact of activity-based mathematics instruction on students with different prior knowledge and reading abilities. International Journal of Science and Mathematics Education, 12(6), 1445-1468. Retrieved from http://www.link.spriger.com

Kolawole, E. B., \& Ajetunmobi, O. (2014). Kolawole's problem solving (KPS) method as a Panacea for mathematical problems and an antidote to mass failure in mathematics examinations Abacus, Journal of the Mathematical Association of Nigeria. Abacus, Journal of the Mathematical Association of Nigeria, 39(1), 159-176.

Nwadiage, A. (2010, 08 28). WAEC records 75\% failure in English Language and Mathematics. The Nations News Paper of August 28, 2010. 1 -2., pp. 1-2.

Odili, G. A. (2006). Mathematics in Nigeria Secondary Schools: A Teaching Perspective. Lagos: Nimorex and Patrick Limited.

Owodunni, A. S., \& Ogundola, I. P. (2013). Gender difference in the achievement and retention of Nigeria students exposed to concept in electronic works trade through reflective inquiry instructional technique. British Journal of Education, Society and Behavioral Science, 3(4), 589-599.

Prem, L. (2012). Problem solving strategy. Retrieved from http://www.eprogressiveportfolio.com.ng/2012/01/problem-solvingstrategy.html 
Salman, M. F., \& Adeniyi, C. O. (2012). Influence of teachers' qualification and experience on secondary school students' academic performance in mathematics. Abacus, the Journal of Mathematical Association of Nigeria, 37(1), 134-141.

Shiri, K. M., \& Badri, Y. (2013). Effect of activity-based approach on achievement in science of students at elementary stage International. International Journal of Basic and Applied Science, 1(4), 694-704.

Thayniath, S. (2016). Activity based language learning in the classroom - an effective learning method. International Journal of English Language, Literature and Humanity, 4(5), 132-141.

Ugwanyi, C. C. (2016). Effect of using algebraic factorization game instructional strategy on students' retention in algebra in Enugu state, Nigeria. Effect of using algebrai Abacus, the Journal of Mathematical Association of Nigeria, 40(1), 169-177.

Wikipedia. (2011). Activity-based learning in India. Retrieved from http//en.wikipedia.org/wiki/Activity-based_learning_in_india. 
Durojaiye, David Sunday; Jekayinfa, Olatunji James; Oloda Festus Sunday Smart

EFFECT OF ACTIVITY-BASED INSTRUCTIONAL STRATEGY ON SENIOR SECONDARY

SCHOOL STUDENTS' RETENTION IN CIRCLE GEOMETRY IN ABUJA, NIGERIA

Creative Commons licensing terms

Author(s) will retain the copyright of their published articles agreeing that a Creative Commons Attribution 4.0 International License (CC BY 4.0) terms will be applied to their work. Under the terms of this license, no permission is required from the author(s) or publisher for members of the community to copy, distribute, transmit or adapt the article content, providing a proper, prominent and unambiguous attribution to the authors in a manner that makes clear that the materials are being reused under permission of a Creative Commons License. Views, opinions and conclusions expressed in this research article are views, opinions and conclusions of the author(s). Open Access Publishing Group and European Journal of Education Studies shall not be responsible or answerable for any loss, damage or liability caused in relation to/arising out of conflicts of interest, copyright violations and inappropriate or inaccurate use of any kind content related or integrated into the research work. All the published works are meeting the Open Access Publishing requirements and can be freely accessed, shared, modified, distributed and used in educational, commercial and non-commercial purposes under a Creative Commons Attribution 4.0 International License (CC BY 4.0). 